arthritis of the right hip. It was then discovered that he had had mild diarrhoea for over 10 years. On examination there were no significant abnormal physical signs except restricted movements of his right hip; no abdominal tumour could be felt. Sigmoidoscopy revealed a moderate degree of proctitis and biopsy showed the features of chronic ulcerative colitis, but there was no premalignant change in the rectal mucosa. Barium enema revealed extensive ulcerative colitis with a constant stricture in the transverse colon (fig. 2). At operation under-

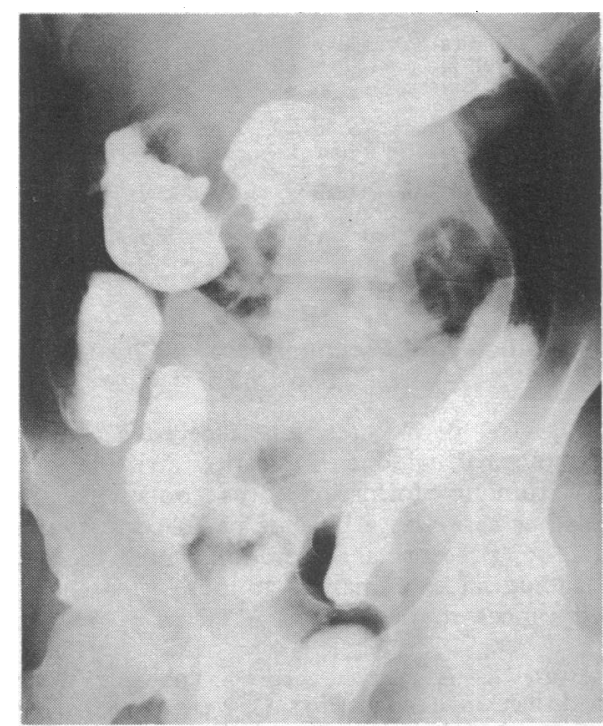

FIG. 2.- - Barium enema showing changes of chronic
ulcerative colitis with constant stricture in transverse colon. Case 2.

taken for removal of the large intestine no tumour could be found; the bowel showed only mild changes on the serosal surface of some increase in vascularity. Likewise examination of the specimen revealed no evidence of a stenosing tumour. Histopathological examination, however, revealed areas of premalignant change and of definite cytological malignancy without invasion.

The absence of a tumour after persistent radiological evidence poses a dilemma for the surgeon, who, when confronted with negative laparotomy findings, may consider panproctocolectomy to be unnecessary. In both cases the disease had persisted for more than 10 years. Case 1 was seen before premalignant changes were described by Morson and Pang'; premalignant changes were present in case 2 but not on rectal biopsy. In the event the radiological changes proved to be correct and the absence of tumour to be seen by the naked eye to be misleading. The absence of tumour in the presence of such obvious radiological change is inexplicable, but this combination has proved to be associated with early malignancy and the radiological sign may be an important indication of this change.-We are, etc.,

BRYAN N. BROOKE

St. George's Hospital, London S.W.17

David Cave

1 Morson, B. C., and Pang, L. S. C., Gut, 1967,

\section{Sponsored Hospitality}

SIR,-I very recently received notification of a meeting of a medical association regional branch. I am a little disquieted to see that refreshments, which are basically wines and a little food, are to be provided by a commercial firm. The proper relationship between us doctors and the drug houses is a matter of real difficulty, however careful we are to maintain our independence. It is inevitable that a large part of our approach to new drugs should be influenced by the approaches of their representatives, who are, indeed, extremely well informed and tell us of particulars in the therapeutic field which are often of great value to our patients.

In these circumstances it is specially important that we should try to retain a full independence of judgement. If I accept hospitality from a commercial organizacion it is hard not to accept the idea that I will consider their products favourably. To do so restricts that independence of judgement which my patients and the Department of Health expect me to exercise on their behalf. To deny such bias, on the other hand, seems unfair to the drug companies. Whatever the rights and wrongs of our remuneration, it cannot be said that the medical profession is a group of impoverished persons. Can we not afford to pay for our own refreshments? -I am, etc.,

Birmingham

KEITH NORCROSS

edly less $(P<0.02)$ when the patients were pretreated with Sch 1000 (mean value 15\% S.E. $3 \cdot 4 \%$ ). A fall in PEF exceeding $20 \%$ of the basal value was obtained in 10 patients with the smaller dose of five breaths of $\mathrm{PGF}_{2} \alpha$ and in the remaining six patients with the larger dose of $5+20$ breaths. Five healthy volunteers inhaled a dose of 45 breaths without developing bronchoconstriction, the fall in PEF ranging from 3\% to $7 \%$.

Our findings seem to support the hypothesis that the bronchoconstrictor effect of the inhalation of $\mathrm{PGF}_{2} \alpha$ is partly mediated via the vagus nerves, and they differ in this respect from those reported by Smith and Cuthbert. The marked local irritant effect, often accompanied by paroxysms of cough, is compatible with the existence of a reflex action component, although Smith and Cuthbert found the response to $\mathrm{PGF}_{2} \alpha$ to be less immediate than that reported for other inhaled irritants. Asthmatics were found to be much more sensitive than heal'hy subjects to inhalation of $\mathrm{PGF}_{2} \alpha$.

Prostaglandin was kindly supplied by the Upiohn Company.

-We are, etc.,

RARI ALANKo Hakan Poppius

University Central Hospital, Helsinki, Finland

\section{Anticholinergie Blocking of}

Prostaglandin-induced Bronchoconstriction

SIR,-Drs. A. P. Smith and M. F. Cuthbert (22 July, p. 212) noted a decrease in specific airway conductance following inhalation of prostaglandin $\mathrm{F}_{2} \alpha\left(\mathrm{PGF}_{2} \alpha\right)$ in healthy subjects. Bronchoconstriction started after a short latent period and usually reached its maximum 4-6 minutes after inhalation. The immediate effect of inhalation was pharyngeal irritation and coughing. They thought that the bronchoconstriction was not due to an irritant effect of $\mathrm{PGF}_{2} \alpha$ because there was a short latent period between the inhalation and the onset of bronchoconstriction, and because earlier inhalation of atropine methonitrate did not influence the reaction.

An open assessment of the preventive effect of the anticholinergic drug Sch 1000 (Boehringer Ingelheim) on $\mathrm{PGF}_{2} \alpha$-induced bronchoconstriction was carried out on 16 asthmatic patients $(10$ males and 6 females, aged 18-67 (mean 37) years). Bronchial hyperreactivity had been demonstrated in each case by means of a histamine inhalation test After peak expiratory flow (PEF) had been recorded the patient inhaled five tidal breath in a standardized manner from a De Vilbiss no. 40 nebulizer containing $0.1 \%$ $\mathrm{PGF}_{2} \alpha$ in saline. With an airflow of 5 1./min the nebulizer delivered approximately $0.4 \mathrm{mg} \mathrm{PGF} 2 \alpha / \mathrm{min}$. PEF was measured again five minutes after the inhalation. If the fall in PEF was less than $20 \%$ of the basal value the patient inhaled a further 20 tidal breaths of $\mathrm{PGF}_{2} \alpha$, and PEF was again measured 5 minutes later. The experiment was performed twice on every patient with one or two days interval, once without pretreatment and once 20 minutes after inhalation of two puffs (40 $\mu \mathrm{g}$ each) of Sch 1000 the order of the two experiments being varied. The mean basal PEF was $3981 . / \mathrm{min}$ when no pretreatment had been given and $4381 . / \mathrm{min}$ after inhalation of Sch 1000.

The smaller dose of $\mathrm{PGF}_{2} \alpha$ was followed SIR,-I think Dr. R. B. Smith's (20 January, by a mean decrease of $25 \%$ in PEF (S.E. p. 177) local executive council is quite right of mean $4 \cdot 1 \%$ ). The fall in PEF was mark- to refuse his request to change his evening 